\title{
Physical Condition, Sex, and Age-Class of Eastern Red-Backed Salamanders (Plethodon cinereus) in Forested and Open Habitats of West Virginia, USA
}

\author{
Breanna L. Riedel, ${ }^{1}$ Kevin R. Russell, ${ }^{1}$ and W. Mark Ford ${ }^{2,3}$ \\ ${ }^{1}$ College of Natural Resources, University of Wisconsin-Stevens Point, Stevens Point, WI 54481, USA \\ ${ }^{2}$ Northern Research Station, USDA Forest Service, Parsons, WV 26287, USA \\ ${ }^{3}$ U.S. Geological Survey, Virginia Cooperative Fish and Wildlife Research Unit, Virginia Polytechnic Institute and State University, \\ Blacksburg, VA 24061, USA
}

Correspondence should be addressed to Kevin R. Russell, krussell@uwsp.edu

Received 7 March 2012; Revised 15 May 2012; Accepted 29 May 2012

Academic Editor: Michael Thompson

Copyright ( $\odot 2012$ Breanna L. Riedel et al. This is an open access article distributed under the Creative Commons Attribution License, which permits unrestricted use, distribution, and reproduction in any medium, provided the original work is properly cited.

\begin{abstract}
Nonforested habitats such as open fields and pastures have been considered unsuitable for desiccation-prone woodland salamanders such as the Eastern Red-backed Salamander (Plethodon cinereus). Recent research has suggested that Plethodon cinereus may not only disperse across but also reside within open habitats including fields, meadows, and pastures. However, presence and high densities of $P$. cinereus within agriculturally disturbed habitats may be misleading if these populations exhibit atypical demographic characteristics or decreased physical condition relative to forest populations. We surveyed artificial cover boards from 2004-2005 to compare physical condition, sex ratios, and age-class structure of P. cinereus among woodland, woodland-meadow edge, silvopasture, and meadow sites in the central Appalachian Mountains of southern West Virginia. Physical condition of salamanders was not significantly different among the four habitats. Furthermore, adult sex ratios of $P$. cinereus typically were not significantly different from $1: 1$ and were similar between forested and non-forested sites, although populations within silvopastures were biased towards females. However, adult salamanders were significantly more abundant than juveniles in all habitat types, with differences most pronounced within meadow habitats. Our study indicates that relatively small, non-forested habitats such as silvopastures and meadows may not adversely affect the overall physical condition or sex ratios of Plethodon cinereus. However, the paucity of juveniles within disturbed meadows indicates that these agriculturally modified habitats may negatively impact reproduction or that immature salamanders are at a physiological or competitive disadvantage in comparison to adults, particularly when surface cover is limited.
\end{abstract}

\section{Introduction}

Woodland salamanders of the family Plethodontidae are among the most abundant vertebrates in the moist temperate forests of North America, with the density of Eastern Redbacked Salamanders (Plethodon cinereus) and other terrestrial Plethodontidae often exceeding 1-2 individuals $/ \mathrm{m}^{2}$ $[1,2]$. Despite these often high densities, many woodland salamander species are restricted to moist and cool environments under leaf litter, downed woody debris and rocks, or in subterranean refugia $[2,3]$. Because of these requirements, many species are associated with microhabitat characteristics indicative of mature and late-successional forests $[2,4]$. Ample research has suggested that forest management practices may cause long-term declines and localized extirpation of woodland salamanders within deciduous forests of eastern North America (e.g., Appalachian Mountains), with the magnitude of responses related to the intensity of overstory removal and forest floor disturbance [4-8]. However, there is other research indicating that some woodland salamander populations in both the southern and central Appalachians may recover from the effects of timber harvest within 25 years of forest overstory removal $[7,8]$. 
Mixed forest-agricultural landscapes are common in the central Appalachians. Grassland management and pasturebased livestock production account for the majority of agricultural acreage and about $25 \%$ of the total land use in the region [9]. If woodland salamander populations decline at least temporarily after timber harvest, conversion of forests to non-forest habitats (e.g., meadows, pastures) in theory should result in more severe and permanent reductions in salamander densities. Additionally, silvopasture management, which combines livestock grazing and forest management, has increased in popularity as an agroforestry land use practice in the Appalachian region [9]. In existing forests, silvopastures are created by heavily thinning stands followed by removal of woody debris and surface rock to promote growth of herbaceous livestock forage [9]. Partial overstory retention in silvopastures may approximate effects of forest thinning or selective timber harvest on salamanders and therefore represent a less severe impact when compared to either clearcutting or traditional pasture conversion. However, in contrast with selective harvest methods the complete removal of surface cover and direct disturbance from livestock grazing in silvopastures may limit suitability of these habitats for woodland salamanders.

Non-forested areas such as open fields and pastures traditionally have been considered unsuitable for Plethodon cinereus and other desiccation-prone woodland salamanders [2, 10]. However, Riedel et al. [11] recently documented large numbers of $P$. cinereus within silvopasture and meadow habitats in southern West Virginia. Factors contributing to the apparent persistence of $P$. cinereus in these disturbed habitats are thought to include retention of dense herbaceous vegetation in combination with the presence of artificial cover objects [11]. These findings potentially contradict our current understanding of woodland salamander ecology and responses of these species to habitat disturbance $[2,4$, 6]. However, if the populations exhibit atypical age-class distributions, sex ratios, or physical condition (e.g., mass), these high population densities may not accurately reflect habitat suitability or population health $[12,13]$. For example, Ash et al. [12] reported that populations of Southern gray-cheeked salamanders (Plethodon metcalfi) found within clearcuts were almost exclusively adults, thereby suggesting that immature salamanders were less likely to survive in open, disturbed habitats when compared to adults. Salamanders in non-forest habitats may be subject to greater rates of desiccation, which in turn limits foraging intake and therefore overall physical condition, reproductive potential, and survivorship [2, 3]. Therefore, our objective was to determine if the physical condition, sex ratios, and age-class structure of $P$. cinereus within forest edge, silvopasture, and traditional pasture-meadow habitats were similar to those for salamanders within intact forest sites. We hypothesized that $P$. cinereus within woodlands would exhibit greater physical condition than salamanders found in disturbed agricultural sites. We also hypothesized that juvenile salamanders would be underrepresented in agricultural habitats, reflecting the decreased suitability of these sites when compared to mature forests.

\section{Materials and Methods}

2.1. Study Area. We conducted our study at the USDA Agricultural Research Service's Appalachian Farming System Research Center (AFSRC) near Beckley, in Raleigh County, West Virginia, USA. The AFSRC occurs within the Allegheny Mountain and Plateau physiographic province of the central Appalachians [11]. Data were collected within 11 sites distributed across three AFSRC experimental farms (Reba, School, Peters) [11] that represented a continuum of forest conversion and grazing intensity: reference woodlands $(N=$ $3)$, woodland edges $(N=3)$, grazed silvopastures $(N=$ 3 ), and traditional hay meadows (hereafter meadows; $N=$ 2 ). Reference woodland stands were $\geq 40$ years old with no cutting for $\geq 25$ years and no known recent history of grazing. Basal area of woodland reference sites was approximately $19.1 \mathrm{~m}^{2} /$ ha. Silvopastures were created from existing woodlands between 1997 and 2002 by reducing overstory basal area from approximately $19.1 \mathrm{~m}^{2} /$ ha to $6.7 \mathrm{~m}^{2} /$ ha. Meadows had been converted from existing woodlands for $\geq 25$ years. Residual overstory trees on woodland and silvopasture plots primarily consisted of mixed mesophyticAllegheny hardwoods dominated by sugar maple (Acer saccharum), red maple (A. rubrum), and black cherry (Prunus serotina). White oak (Quercus alba), black oak ( $Q$. velutina), and blackgum (Nyssa sylvatica) occurred on the less mesic, somewhat drier aspects, whereas eastern hemlock (Tsuga canadensis) and rosebay rhododendron (Rhododendron maximum) dominated nearby adjacent riparian areas. Ground cover of woodland plots consisted of herbaceous species, woody debris, and abundant emergent rock. However, essentially all woody debris and rocks were removed from silvopasture, meadow, and pasture plots. Common herbaceous or grassy species within pasture and silvopasture plots included cinquefoil (Potentilla recta), orchardgrass (Dactylis glomerata), ryegrass (Lolium perenne), tall fescue (Festuca arundinacea), and white clover (Trifolium repens). Silvopastures were grazed by domestic sheep (Ovis aries) at a density of 12-24 sheep/ha with a 5-7 day rotation and 2535 day rest period. The two traditional hay meadows were not grazed during the study but were mowed 1 time per year. Additional details of the study sites are described in Riedel et al. [11].

2.2. Salamander Sampling. Between 2002 and 2004, we established arrays of 20 wood coverboards [14, 15] in each of the 11 sites. A small number of coverboards was established on Reba farm in 2002 as part of an earlier pilot study, but most coverboards at the three farms were established in late 2003 and early 2004. Data from the 2002 pilot study were not included in our study. Because salamanders may avoid newly installed coverboards [14], our arrays were established at least one month prior to data collection. Arrays at woodland edge sites consisted of two rows of boards parallel to the forest edge. We placed one row approximately $10 \mathrm{~m}$ inside and we placed the other row an equal distance outside the woodland boundary. Each row consisted of 10 boards spaced approximately $15 \mathrm{~m}$ apart. A $4 \times 5$ grid of boards was established within each of the remaining 8 sites, with 
boards spaced approximately $15 \mathrm{~m}$ apart. Within these sites, coverboards were $\geq 30 \mathrm{~m}$ from habitat edges. Research in West Virginia examining woodland salamander responses to edge effects with edge types similar to those in our study area (i.e., woodlands adjacent to permanent grassy openings) indicated that woodland salamander responses were largely confined to within $20 \mathrm{~m}$ of opening edges [16]. Coverboards consisted of three white oak boards, with two boards on the bottom and one board placed on top for a total dimension of $30 \mathrm{~cm} \times 46 \mathrm{~cm} \times 5 \mathrm{~cm}$. We removed all surface debris from under the boards so that each board lay flush against the topsoil.

We checked coverboards weekly from 17 May to 10 August 2004, and then again 1-2 times monthly between September and December. In 2005, we checked coverboards once in March and April, weekly during 30 May-2 August, and then again monthly from September to November. During 2004 and 2005, approximately 65\% of total Plethodon cinereus captures in the study area occurred between September and December [17]. Our searches were performed during the day, and we made attempts to check all boards over the course of two days to avoid time since rainfall effects [18]. We recorded the following information for each captured salamander: species, snout-vent length (SVL) and tail length (nearest $0.1 \mathrm{~mm}$ ), mass (nearest $0.01 \mathrm{~g}$ ), juvenile or adult age class (juveniles $\leq 34 \mathrm{~mm} \mathrm{SVL}$; [2]), and presence of previous marks. We also noted whether tail autotomy had occurred and measured the length of the regenerated portion of the tail on salamanders that experienced tail loss [3]. We determined sex and presence and number of eggs by holding salamanders up to a fiber-optic light [19]. We identified males by the presence of pigmented testes and inspection of external morphological characteristics (e.g., internares difference, head shape, swollen mental, and nasolabial glands; $[2,20])$.

We marked salamanders for individual recognition by toe clipping or injecting a small amount of fluorescent elastomer (Northwest Marine Technology Inc., Shaw Island, WA, USA) at up to four body locations (base of each limb; [21]). After marking, we released salamanders next to the coverboard.

2.3. Analysis. Physical condition is an important determinant of individual fitness [22]. Salamanders of relatively high mass for their length are assumed to be in better physical and physiological condition than those of relatively low mass for their length [3]. Salamanders with better physical condition are assumed to exhibit increased foraging success and therefore greater survivorship and reproductive success than individuals with poor physical condition. Woodland salamanders are assumed to experience greater rates of desiccation within non-forested habitats, which in turn limits foraging activity and therefore mass. Indices of physical condition attempt to determine the mass of the individual associated with energy reserves after correcting for body size [22, 23]. We used a common method for measuring physical condition that regressed body mass on a linear index of body size and used the residuals from this regression as an index of physical condition [22-24].
Individuals with positive residuals are considered to be in better condition than individuals with negative residuals $[22,24]$. Because weight increases with age, the process error around the weight-length relationships is multiplicative, not additive. Therefore, we log transformed the model to estimate the parameters using linear regression with additive errors. We defined physical condition of a salamander as the residual of the regression of log mass on log SVL. Because body condition changes with age, $\log ($ mass $)-\log (\mathrm{SVL})$ residuals can be confounded with age $[22,25]$. Therefore, we calculated residual indices separately for adult and juvenile salamander age classes.

Plethodon cinereus commonly experience tail loss, and tail autonomy could influence body mass that is not accounted for by SVL, thereby biasing condition indices. However, the frequency of tail autonomy was similar among treatments $\left(\chi^{2}=2.12, P=0.463\right)$. Consequently, differences in condition indices among treatments were not likely influenced by tail autonomy.

We used a two-way analysis of variance [26] to determine if physical condition of salamanders varied by sex among woodland reference, edge, silvopasture, and meadow habitats. Because the determination of sex for immature salamanders is unreliable without dissection, we did not specify gender for individuals $\leq 34 \mathrm{~mm}$ SVL.

We used $G$-tests to determine if sex ratios and age class of salamander populations varied among treatments. We examined sex and age ratios from two different perspectives. First, we conducted G-tests of goodness-of-fit using expected adult sex ratios and juvenile to adult ratios of $1: 1$. Because sample sizes were low, we used the $G$-statistic with Williams' correction [27] and set statistical significance at $\alpha=0.05$. The adult sex ratio of Plethodon cinereus usually does not differ from $1: 1[2,28,29]$. Reported age ratios of $P$. cinereus are more variable, with some studies reporting significantly more adults than juveniles [30-32], whereas others have reported an approximately $1: 1$ ratio of juveniles to adults [33]. Second, we conducted multiple $G$-tests of independence to individually compare $P$. cinereus age and adult sex ratios from edge, silvopasture, and meadow treatments to those in woodland reference treatments rather than assuming $1: 1$ ratios. We set statistical significance at $\alpha \leq 0.0167$ for these multiple comparisons. Using both approaches allowed us to determine if $P$. cinereus populations within each habitat type varied from hypothetical 1:1 sex and age-class ratios as well as to determine if populations within agriculturally disturbed habitats were reflective of those actually observed within reference woodlands, assuming that intact, closed canopy forests represent the most suitable habitat conditions for $P$. cinereus regionally. Captures were corrected for the unequal number of meadow treatments and recaptures were omitted from all analyses.

\section{Results}

Length, mass, sex, and age-class data were obtained from 527 individual Plethodon cinereus in the four habitat types between 2004 and 2005 (Table 1). 
TABle 1: The number of captures (N), mean snout-vent length (SVL; mm), and mean mass (g) of adult female, adult male, and juvenile Plethodon cinereus within woodland, woodland edge, silvopasture, and meadow habitats in southern West Virginia, 2004-2005. Means are reported $\pm 1 \mathrm{SD}$.

\begin{tabular}{|c|c|c|c|c|c|c|c|c|c|}
\hline \multirow{2}{*}{ Habitat } & \multicolumn{3}{|c|}{ Adult female } & \multicolumn{3}{|c|}{ Adult male } & \multicolumn{3}{|c|}{ Juvenile } \\
\hline & $N$ & SVL & Mass & $N$ & SVL & Mass & $N$ & SVL & Mass \\
\hline Woodland reference & 51 & $40.1 \pm 3.2$ & $1.0 \pm 0.3$ & 53 & $41.9 \pm 3.6$ & $1.1 \pm 0.3$ & 72 & $29.7 \pm 4.4$ & $0.5 \pm 0.2$ \\
\hline Woodland edge & 53 & $40.3 \pm 3.6$ & $1.1 \pm 0.3$ & 61 & $42.0 \pm 3.1$ & $1.2 \pm 0.3$ & 53 & $29.2 \pm 3.7$ & $0.5 \pm 0.2$ \\
\hline Silvopasture & 30 & $42.4 \pm 2.6$ & $1.3 \pm 0.2$ & 16 & $42.5 \pm 3.9$ & $1.3 \pm 0.3$ & 25 & $25.5 \pm 5.2$ & $0.4 \pm 0.2$ \\
\hline Meadow & 48 & $38.5 \pm 3.5$ & $1.0 \pm 0.2$ & 52 & $41.2 \pm 4.1$ & $1.2 \pm 0.3$ & 17 & $32.3 \pm 1.8$ & $0.6 \pm 0.1$ \\
\hline Total & 182 & & & 180 & & & 165 & & \\
\hline
\end{tabular}

TABle 2: Numbers of adult male, female, and juvenile Plethodon cinereus from four habitats in southern West Virginia, 2004-2005, with results of $G$-tests using Williams' correction for deviations from hypothetical $1: 1$ sex- and age-class ratios. ${ }^{*} P \leq 0.05$.

\begin{tabular}{|c|c|c|c|c|c|}
\hline \multirow{2}{*}{ Habitat } & \multicolumn{2}{|c|}{ Adults } & \multicolumn{2}{|c|}{ Juveniles } & \multirow[b]{2}{*}{ Gadj } \\
\hline & Observed & Expected & Observed & Expected & \\
\hline Woodlands & 104 & 88.0 & 72 & 88.0 & $7.60^{*}$ \\
\hline Woodland edges & 114 & 83.5 & 53 & 83.5 & $25.91^{*}$ \\
\hline Silvopastures & 46 & 35.5 & 25 & 35.5 & $6.26^{*}$ \\
\hline Meadows & 100 & 58.5 & 17 & 58.5 & $66.01^{*}$ \\
\hline Total & 364 & 265.5 & 167 & 265.5 & \\
\hline \multirow{2}{*}{ Habitat } & \multicolumn{2}{|c|}{ Females } & \multicolumn{2}{|c|}{ Males } & \\
\hline & Observed & Expected & Observed & Expected & Gadj \\
\hline Woodlands & 51 & 52 & 53 & 52 & 0.04 \\
\hline Woodland edges & 53 & 57 & 61 & 57 & 0.56 \\
\hline Silvopastures & 30 & 23 & 16 & 23 & $4.28^{*}$ \\
\hline Meadows & 48 & 50 & 52 & 50 & 0.16 \\
\hline Total & 182 & 182 & 182 & 182 & \\
\hline
\end{tabular}

3.1. Physical Condition. The mean physical condition of salamanders was not significantly different among reference woodland, edge, silvopasture, or meadow habitats $(F=1.69$, $P=0.196)$. Mean physical condition was similar between adult males and females $(F=0.15, P=0.858)$. We also found no significant interaction between sex and habitat effects on physiological condition of salamanders $(F=0.86$, $P=0.536)$.

3.2. Sex Ratios. The ratio of adult males to adult females was not significantly different from $1: 1$ within woodland, woodland edge, and meadow habitats (Table 2). In contrast, the sex ratio within silvopastures deviated significantly from $1: 1$ (Table 2), with nearly twice as many females than males observed in this habitat type (Table 1). Direct comparisons between woodland reference sites and the three agriculturally disturbed habitats indicated no significant difference in adult sex ratios of $P$. cinereus (Table 3 ).

3.3. Age-Class Ratios. The ratio of adult to juvenile salamanders was significantly different than $1: 1$ within all four habitat types (Table 2), with adults ranging from 1.4 times (reference woodlands) to 5.9 times (meadows) more abundant than juveniles (Table 1). Additionally, when compared to the ratio of adults to juveniles observed within reference woodlands, meadow habitats contained significantly more adults than reference woodlands (Table 3 ).

\section{Discussion}

Open habitats such as early successional forest, meadows, and field-forest edges previously have been thought to be unsuitable or marginal habitats for both pond-breeding amphibians and terrestrial but moisture-sensitive woodland salamanders [2, 34, 35]. Increased surface temperatures and decreased soil moisture associated with open habitats and forest edges conceivably should lead to increased rates of desiccation and therefore increased time spent by salamanders in fossorial refugia, effectively reducing foraging opportunities $[12,13,36]$. Hydration constraints and reduced foraging within agriculturally disturbed habitats should therefore be expected to negatively affect the body condition of Plethodon cinereus. However, our results failed to support the hypothesis that $P$. cinereus within meadows, silvopastures, and along forest-field edges would exhibit lesser physical condition when compared to salamanders in forest habitats. Interestingly, Knapp et al. [13] reported that the size-corrected mass (mass/SVL) of gravid $P$. cinereus 
TABle 3: Results of G-tests of independence comparing age-class and sex ratios of Plethodon cinereus between reference woodlands and three agriculturally disturbed habitats in southern West Virginia, 2004-2005. Numbers of captures within each habitat type are separated by commas. Significance was set at $P \leq 0.0167$ and $\mathrm{df}=1$ for all comparisons.

\begin{tabular}{|c|c|c|c|c|}
\hline Habitat comparison & Adults $(N, N)$ & Juveniles $(N, N)$ & $G$ & $P$ \\
\hline Woodlands versus edges & 104,114 & 72,53 & 3.12 & 0.077 \\
\hline Woodlands versus silvopastures & 104,46 & 72,25 & 0.69 & 0.405 \\
\hline Woodlands versus meadows & 104,100 & 72,17 & 24.69 & $<0.0001$ \\
\hline Habitat comparison & Females $(N, N)$ & Males $(N, N)$ & $G$ & $P$ \\
\hline Woodlands versus edges & 51,53 & 53,61 & 0.14 & 0.707 \\
\hline Woodlands versus silvopastures & 51,30 & 53,16 & 3.41 & 0.065 \\
\hline Woodlands versus meadows & 51,48 & 53,52 & 0.02 & 0.882 \\
\hline
\end{tabular}

was actually higher on recently harvested sites than within mature forests in the southern Appalachian Mountains of Virginia and West Virginia, suggesting that forest canopy removal did not adversely impact physical condition.

The apparent lack of differences in physical condition of salamanders inhabiting forest and open habitats may indicate that Plethodon cinereus is more tolerant of habitat alterations than previously suspected $[10,11,37,38]$. Woodland salamander habitat suitability is strongly influenced by surface moisture levels $[3,6,7]$. Sufficient availability of natural cover objects (e.g., coarse woody debris) has been found to at least partially mitigate the microclimatic effects of forest edges on woodland salamanders [38]. Indeed, Riedel et al. [11] recently reported large populations of $P$. cinereus within silvopasture, meadow, and forest edge habitats of West Virginia. In fact, meadow habitats supported higher relative abundances of salamanders than did reference woodlands [11]. This persistence of $P$. cinereus within these open habitats was thought attributable to retention of dense patches of herbaceous vegetation that retained sufficient groundlevel moisture, along with the presence of artificial cover objects. Similarly, Marsh et al. [10] reported that $P$. cinereus successfully colonized artificial coverboards within fields, suggesting that cover objects mitigated adverse climatic conditions within early successional habitats. Therefore, sufficient cover availability within agriculturally disturbed habitats may mitigate adverse microclimatic conditions that could negatively influence the physical condition of woodland salamanders.

Another explanation for similar indices of physical condition between forest and open habitats is that the salamanders we observed in forest edges, silvopastures, and meadows were recent dispersers from adjacent forests rather than established residents. If true, then it is possible that potential negative effects of open habitats on the body condition on $P$. cinereus had yet to be displayed fully by the extant individuals. However, Marsh et al. [10] observed that early colonizers of field habitats were younger salamanders rather than older and larger adults with dispersing salamanders attempting to establish new territories. Plethodon cinereus are highly territorial and larger, older salamanders generally have a territorial advantage [39], likely forcing younger and smaller salamanders to disperse into lower quality habitats $[10,40]$. In our study, we observed that silvopastures, meadows, and forest edges were populated predominantly by adult $P$. cinereus rather than smaller juveniles, suggesting that the majority of salamanders within these open habitats were residents rather than dispersers.

Although Test and Bingham [33] reported an approximately $1: 1$ ratio of juvenile to adult Plethodon cinereus, several studies have reported higher proportions of adult $P$. cinereus when compared to juveniles [30-32]. Therefore, it is perhaps not surprising that we also found significantly more adults when compared to juveniles. Juveniles often move into adult territories during dry weather but disperse out of these territories into leaf litter during wet weather [41]. Because we timed our coverboard sampling to coincide with precipitation events, we may have missed some juveniles that had dispersed into adjacent forests. We also sampled less frequently in the fall months when small, recently hatched salamanders can represent a larger proportion of the surface population $[2,30,33]$. However, approximately $65 \%$ of all $P$. cinereus captures in the study area occurred between September and December [17], suggesting that sample sizes were adequate during this period to characterize age ratios.

Although juvenile salamanders were underrepresented in all habitat types, including woodlands, the effect was most pronounced in meadow sites. There are several possible explanations for our observation that juvenile Plethodon cinereus were significantly underrepresented within meadow habitats. First, juvenile salamanders may experience decreased survival in open, disturbed habitats when compared to larger adults [12, 13]. Ash et al. [12] reported that immature Plethodon metcalfi were underrepresented in recently clearcut forests. Because of their larger surface area to volume ratios when compared to adults, juvenile salamanders are less able to remain hydrated in areas with reduced canopy cover $[12,42,43]$. In contrast, larger adults may persist longer in poor-quality habitats because they are less prone to desiccation [44] and better able to defend cover objects and burrows $[39,45]$. Second, the paucity of juveniles within meadow treatments may indicate that onsite reproduction was poor [12, 13]. Ash et al. [12] reported that male P. metcalfi within clearcuts did not appear to be reproductively active, and speculated that canopy removal may disrupt reproduction of woodland salamanders. Third, restricted availability of cover objects and the territorial behavior of $P$. cinereus may have limited the presence of 
juveniles $[39,43]$. Territorial defense by $P$. cinereus often is centered on a cover object that is defended against both conspecific and heterospecific intruders, with larger, older individuals generally having a territorial advantage, particularly if cover objects are limited [39, 46, 47]. Within silvopastures and meadows, essentially all natural cover objects (e.g., woody debris, surface rock) had previously been removed to facilitate livestock grazing or mowing, leaving only the artificial coverboards as potential refugia [11]. Our results suggest that the artificial cover objects in meadows, edges, and silvopastures were largely occupied by adult and presumably resident salamanders. Therefore, although juvenile salamanders may readily disperse into fields, meadows, and other open habitats $[10,39,48]$, when cover objects are limited in availability these individuals may be largely prevented from successfully colonizing the site by older, competitively dominant salamanders.

The adult sex ratio of surface-active Plethodon cinereus and other woodland salamanders usually does not significantly differ from $1: 1[2,28,29,49]$. Similarly, in our study the adult sex ratio of adult $P$. cinereus within woodlands, woodland edges, and meadows was not significantly different from $1: 1$. When skewed sex ratios have been reported for woodland salamanders, typically they have been biased in favor of males [49-51]. Male-biased sex ratios in plethodontid salamanders have been attributed to potentially more time spent by males on the surface of the forest floor as they search for mates [51] or that a significant proportion of females in the population are underground brooding eggs [49]. Therefore, we were surprised to find that the adult sex ratio of $P$. cinereus within silvopasture habitats was significantly biased in favor of females, particularly given that sex ratios in the other habitats were unbiased. It is possible that habitat disturbances unique to the silvopastures selectively impacted male but not female salamanders. For example, surface-disturbing practices within silvopastures included rotational grazing by sheep and annual applications of nitrogen-phosphate-potassium fertilizer [11]. However, Williams [52] found no significant differences in the adult sex ratios of six species of plethodontid salamanders after canopy removal and ground disturbances associated with clearcutting in the central Appalachians. It is also possible that female-biased sex ratios within silvopastures were a sampling artifact associated with the use of artificial coverboards. However, such biases were not evident in the other habitat types, including meadows, and Marsh and Goicochea [43] reported that there were no significant differences in the adult sex ratios of $P$. cinereus under coverboards versus natural cover objects. Therefore, we think a more plausible alternative is that the female-biased sex ratios we observed within silvopastures simply reflect natural population variation. For example, Marvin [49] observed that some populations of Cumberland Plateau salamanders (Plethodon kentucki) exhibited female-biased sex ratios in some years but not in others.

Land managers must consider population parameters other than simple counts of abundance or density when predicting effects of canopy removal and other habitat disturbances on woodland salamanders [10-12]. The widespread occurrence and high densities of Plethodon cinereus within agriculturally disturbed habitats [11] may be misleading if these sites are incapable of supporting resident populations (e.g., sink habitats; [53]) or if the populations exhibit atypical demographic characteristics or physical condition when compared to forest populations [12]. Our results suggest that relatively small, open habitats such as silvopastures and meadows may not adversely affect the physical condition or sex ratios of $P$. cinereus. Similarly, Marsh et al. [10] found that dispersal of $P$. cinereus was not limited by the presence of forest cover and suggested that this species may be relatively insensitive to the creation of small, intervening, open habitats such as fields, power line corridors, and even small residential areas. However, our results do suggest that juvenile salamanders may be at a competitive disadvantage within open, agriculturally disturbed habitats, particularly when natural surface cover is limited. Regardless, increasing evidence indicates that $P$. cinereus may be less sensitive to changes in forest composition and structure than previously thought and in fact may be relatively tolerant of environmental conditions found within non-forest habitats $(11,12$, 37). Therefore, suggestions that $P$. cinereus are indicators of the status of other woodland salamander species as well as forest ecosystem function and integrity in general $[2,54]$ may need to be revisited. We caution that our results should not be extrapolated to other species of woodland salamanders, which typically are less widespread than $P$. cinereus and restricted to a more narrow range of habitat conditions (2, $4,5)$.

Although the rugged topography of the central Appalachians has restricted the development of large-scale agricultural activity, smaller-scale land clearing and farm ownership have been present in these landscapes at variable levels since the European settlement. Concurrently, opportunities to employ silvopastures and other agroforestry systems are increasing in the region [9]. Therefore, we suggest that the effects of forest conversion and agricultural management on population parameters of Plethodon cinereus and other woodland salamanders continue to be monitored until we have a better understanding of the long-term consequences of these practices.

\section{Acknowledgments}

The authors would like to thank the USDA Agricultural Research Service Appalachian Farming Service Research Center (AFSRC), USDA Forest Service Northern Research Station, and University of Wisconsin-Stevens Point for financial and logistical support of this research. They thank K. O'Neill, H. Godwin, D. Belesky, J. Neel, and other AFSRC staff for their assistance with this work. B. Harter, M. McDougal, and M. Allen provided valuable field assistance. Animals were captured, handled, and marked in accordance with the University of Wisconsin-Stevens Point IACUC standards. M. Hansen, L. Werner, and three anonymous reviewers provided helpful comments on an earlier draft of this paper. 


\section{References}

[1] T. M. Burton and G. E. Likens, "Salamander populations and biomass in the Hubbard Brook Experimental Forest, New Hampshire," Copeia, vol. 1975, pp. 541-546, 1975.

[2] J. W. Petranka, Salamanders of the United States and Canada, Smithsonian Institution Press, Washington, DC, USA, 1998.

[3] M. C. Grover, "Influence of cover and moisture on abundances of the terrestrial salamanders Plethodon cinereus and Plethodon glutinosus," Journal of Herpetology, vol. 32, no. 4, pp. 489-497, 1998.

[4] J. W. Petranka, M. E. Eldridge, and K. E. Haley, "Effects of timber harvesting on southern Appalachian salamanders," Conservation Biology, vol. 7, no. 2, pp. 363-370, 1993.

[5] J. A. Homyack and C. A. Haas, "Long-term effects of experimental forest harvesting on abundance and reproductive demography of terrestrial salamanders," Biological Conservation, vol. 142, no. 1, pp. 110-121, 2009.

[6] P. G. deMaynadier and M. L. Hunter Jr., "Relationship between forest management and amphibian ecology: a review of the North American literature," Environmental Reviews, vol. 3, pp. 230-261, 1995.

[7] K. R. Russell, T. B. Wigley, W. M. Baughman, H. G. Hanlin, and W. M. Ford, "Responses of southeastern amphibians and reptiles to forest management: a review," in Southern Forest Science: Past, Present, and Future, H. M. Rauscher and K. Johnsen, Eds., GTR SRS-75, pp. 319-334, USDA Forest Service, Asheville, NC, USA, 2004.

[8] C. E. Moorman, K. R. Russell, and C. H. Greenberg, "Reptile and amphibian response to hardwood forest management and early successional habitat," in Ecology and Management of Early Successional Habitats in the Central Hardwood Region, USA, C. H. Greenberg, B. Collins, and F. R. Thompson, Eds., pp. 191-208, Springer, The Netherlands, 2011.

[9] A. L. Buergler, Forage production and nutritive value in a temperate Appalachian silvopasture [M.S. thesis], Virginia Polytechnic Institute and State University, Blacksburg, Va, USA, 2004.

[10] D. M. Marsh, K. A. Thakur, K. C. Bulka, and L. B. Clarke, "Dispersal and colonization through open fields by a terrestrial, woodland salamander," Ecology, vol. 85, no. 12, pp. 33963405, 2004.

[11] B. L. Riedel, K. R. Russell, W. M. Ford, K. P. O’Neill, and H. W. Godwin, "Habitat relationships of eastern red-backed salamanders (Plethodon cinereus) in Appalachian agroforestry and grazing systems," Agriculture, Ecosystems and Environment, vol. 124, no. 3-4, pp. 229-236, 2008.

[12] A. N. Ash, R. C. Bruce, J. Castanet, and H. Francillon-Vieillot, "Population parameters of Plethodon metcalfi on a 10-yearold clearcut and in nearby forest in the southern Blue Ridge Mountains," Journal of Herpetology, vol. 37, no. 2, pp. 445-452, 2003.

[13] S. M. Knapp, C. A. Haas, D. N. Harpole, and R. L. Kirkpatrick, "Initial effects of clearcutting and alternative silvicultural practices on terrestrial salamander abundance," Conservation Biology, vol. 17, no. 3, pp. 752-762, 2003.

[14] L. Monti, M. Hunter, and J. Witham, "An evaluation of the artificial cover object (ACO) method for monitoring populations of the redback salamander Plethodon cinereus," Journal of Herpetology, vol. 34, no. 4, pp. 624-629, 2000.

[15] E. J. Hyde and T. R. Simons, "Sampling plethodontid salamanders: sources of variability," Journal of Wildlife Management, vol. 65 , no. 4 , pp. 624-632, 2001.
[16] K. R. Moseley, W. M. Ford, and J. W. Edwards, "Local and landscape scale factors influencing edge effects on woodland salamanders," Environmental Monitoring and Assessment, vol. 151, no. 1-4, pp. 425-435, 2009.

[17] B. L. Riedel, Habitat relationships of red-backed salamanders (Plethodon cinereus) in Appalachian grazing systems [M.S. thesis], University of Wisconsin-Stevens Point, Stevens Point, Wis, USA, 2006.

[18] J. D. Moore, "Use of native dominant wood as a new coverboard type for monitoring eastern red-backed salamanders," Herpetological Review, vol. 36, no. 3, pp. 268-271, 2005.

[19] J. R. Gillette and M. G. Peterson, "The benefits of transparency: candling as a simple method for determining sex in red-backed salamanders (Plethodon cinereus)," Herpetological Review, vol. 32, no. 4, pp. 233-235, 2001.

[20] V. S. Quinn and B. M. Graves, "A technique for sexing red-backed salamanders (Plethodon cinereus)," Herpetological Review, vol. 30, no. 1, p. 32, 1999.

[21] T. M. Davis and K. Ovaska, "Individual recognition of amphibians: effects of toe clipping and fluorescent tagging on the salamander Plethodon vehiculum," Journal of Herpetology, vol. 35, no. 2, pp. 217-225, 2001.

[22] A. J. Green, "Mass/length residuals: measures of body condition or generators of spurious results?" Ecology, vol. 82, no. 5, pp. 1473-1483, 2001.

[23] A. I. Schulte-Hostedde, B. Zinner, J. S. Millar, and G. J. Hickling, "Restitution of mass-size residuals: validating body condition indices," Ecology, vol. 86, no. 1, pp. 155-163, 2005.

[24] E. M. Jakob, S. D. Marshall, and G. W. Uetz, "Estimating fitness: a comparison of body condition indices," Oikos, vol. 77, no. 1, pp. 61-67, 1996.

[25] S. J. Omerod and S. J. Tyler, "Assessments of body condition in Dippers Cinclus cinclus: potential pitfalls in the derivation and use of condition indices based on body proportions," Ringing and Migration, vol. 11, pp. 31-41, 1990.

[26] J. H. Zar, Biostatistical Analysis, Prentice Hall, Upper Saddle River, NJ, USA, 1996.

[27] R. R. Sokal and F. J. Rolf, Biometry, W. H. Freeman and Company, San Francisco, Cailf, USA, 2nd edition, 1981.

[28] H. H. Hood, "A note on the red-backed salamander at Rochester, New York," Copeia, vol. 1934, pp. 141-142, 1934.

[29] A. Mathis, "Territories of male and female terrestrial salamanders: costs, benefits, and intersexual spatial associations," Oecologia, vol. 86, no. 3, pp. 433-440, 1991.

[30] A. Sayler, "The reproductive ecology of the red-backed salamander, Plethodon cinereus, in Maryland," Copeia, vol. 1966, pp. 183-193, 1966.

[31] J. D. Moore and R. L. Wyman, "Eastern red-backed salamanders (Plethodon cinereus) in a highly acid forest soil," American Midland Naturalist, vol. 163, no. 1, pp. 95-105, 2010.

[32] J. W. Nagel, "Life history of the red-backed salamander, Plethodon cinereus, in northeastern Tennessee," Herpetologica, vol. 33, pp. 13-18, 1977.

[33] F. H. Test and B. A. Bingham, "Census of a population of the red-backed salamander (Plethodon cinereus)," The American Midland Naturalist, vol. 39, pp. 362-372, 1948.

[34] B. B. Rothermel and R. D. Semlitsch, "An experimental investigation of landscape resistance of forest versus old-field habitats to emigrating juvenile amphibians," Conservation Biology, vol. 16, no. 5, pp. 1324-1332, 2002.

[35] T. A. G. Rittenhouse and R. D. Semlitsch, "Grasslands as movement barriers for a forest-associated salamander: migration 
behavior of adult and juvenile salamanders at a distinct habitat edge," Biological Conservation, vol. 131, no. 1, pp. 14-22, 2006.

[36] G. I. Young and R. H. Yahner, "Distribution of, and Microhabitat Use by, Woodland Salamanders Along Forest-Farmland Edges," Canadian Field-Naturalist, vol. 117, no. 1, pp. 19-24, 2003.

[37] J. P. Gibbs, "Distribution of woodland amphibians along a forest fragmentation gradient," Landscape Ecology, vol. 13, no. 4, pp. 263-268, 1998.

[38] K. R. Moseley, W. M. Ford, and J. W. Edwards, "Local and landscape scale factors influencing edge effects on woodland salamanders," Environmental Monitoring and Assessment, vol. 151, no. 1-4, pp. 425-435, 2009.

[39] A. Mathis, "Territoriality in a terrestrial salamander: the influence of resource quality and body size," Behaviour, vol. 112, no. 3-4, pp. 162-175, 1990.

[40] A. L. Moore, C. E. Williams, T. H. Martin, and W. J. Moriarity, "Influence of season, geomorphic surface and cover item on capture, size and weight of desmognathus ochrophaeus and Plethodon cinereus in Allegheny Plateau riparian forests," American Midland Naturalist, vol. 145, no. 1, pp. 39-45, 2001.

[41] R. G. Jaeger, J. A. Wicknick, M. R. Griffis, and C. D. Anthony, "Socioecology of a terrestrial salamander: juveniles enter adult territories during stressful foraging periods," Ecology, vol. 76, no. 2, pp. 533-543, 1995.

[42] R. G. Jaeger, "Microhabitats of a terrestrial forest salamander," Copeia, vol. 1980, pp. 265-268, 1980.

[43] D. M. Marsh and M. A. Goicochea, "Monitoring terrestrial salamanders: biases caused by intense sampling and choice of cover objects," Journal of Herpetology, vol. 37, no. 3, pp. 460466, 2003.

[44] J. R. Spotila, "Role of temperature and water in the ecology of lungless salamanders," Ecological Monographs, vol. 42, pp. 95-125, 1972.

[45] R. G. Jaeger and D. C. Forester, "Social behavior of plethodontid salamanders," Herpetologica, vol. 49, pp. 163-175, 1993.

[46] R. G. Jaeger, D. Kalvarsky, and N. Shimizu, "Territorial behaviour of the red-backed salamander: expulsion of intruders," Animal Behaviour, vol. 30, no. 2, pp. 490-496, 1982.

[47] E. M. Smith and F. H. Pough, "Intergeneric aggression among salamanders," Journal of Herpetology, vol. 28, no. 1, pp. 41-45, 1994.

[48] P. G. Demaynadier and M. L. Hunter Jr., "Effects of silvicultural edges on the distribution and abundance of amphibians in maine," Conservation Biology, vol. 12, no. 2, pp. 340-352, 1998.

[49] G. A. Marvin, "Life history and population characteristics of the salamander Plethodon kentucki with a review of Plethodon life histories," American Midland Naturalist, vol. 136, no. 2, pp. 385-400, 1996.

[50] R. J. Hall and D. P. Stafford, "Studies in the life history of Wehrle's salamander, Plethodon wehrle," Herpetologica, vol. 28, pp. 300-309, 1972.

[51] K. Ovaska and P. T. Gregory, "Population structure, growth, and reproduction in a Vancouver Island population of the salamander Plethodon vehiculum," Herpetologica, vol. 45, no. 2, pp. 133-143, 1989.

[52] L. A. Williams, Amphibian population and community characteristics, habitat relationships, and first-year responses to clearcutting in a central Appalachian industrial forest [M.S. thesis], Virginia Polytechnic Institute and State University, Blacksburg, Va, USA, 2003.

[53] H. R. Pulliam, "Sources, sinks and population regulation," American Naturalist, vol. 132, no. 5, pp. 652-661, 1988.
[54] H. H. Welsh and S. Droege, "A case for using plethodontid salamanders for monitoring biodiversity and ecosystem integrity of north american forests," Conservation Biology, vol. 15, no. 3, pp. 558-569, 2001. 

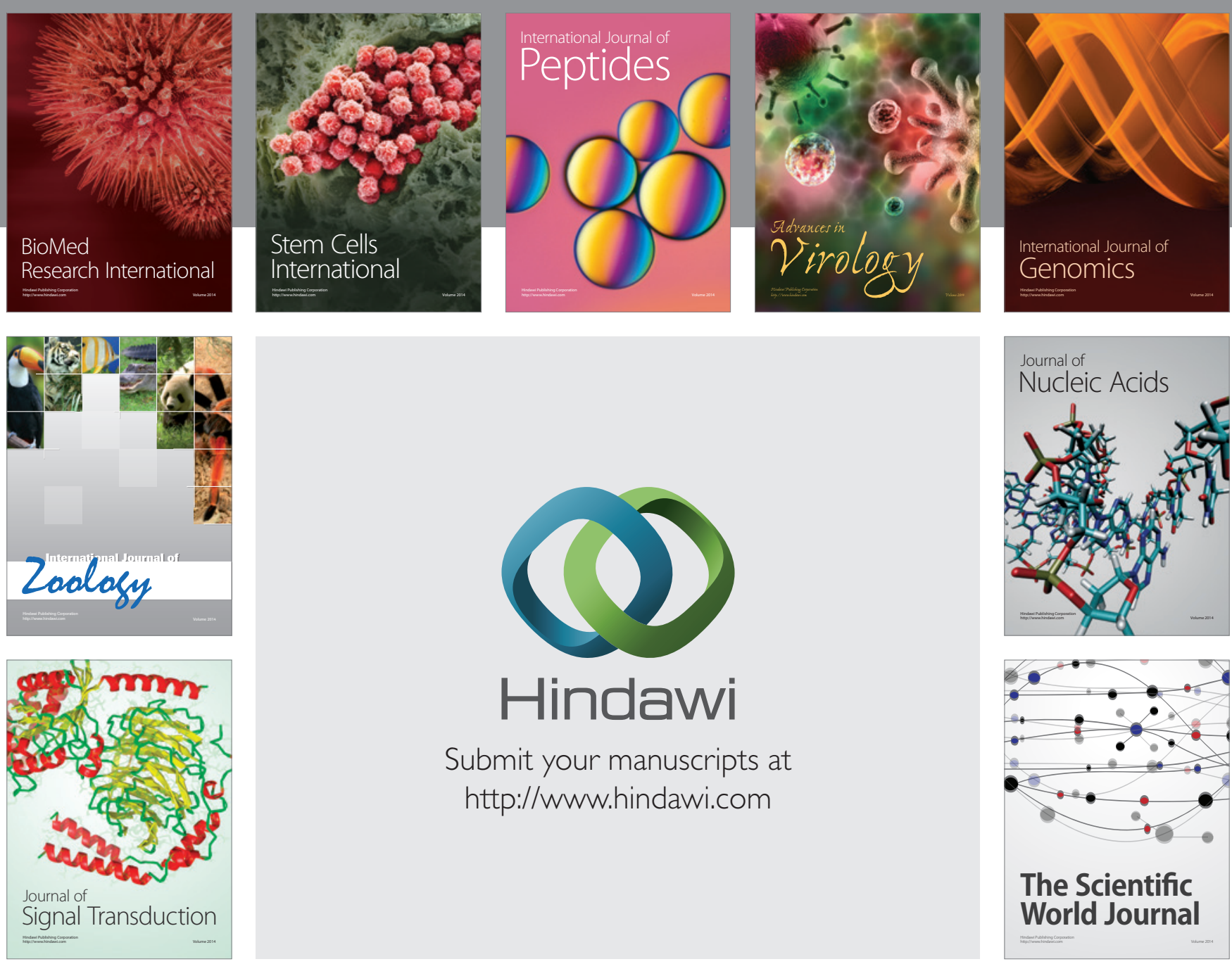

Submit your manuscripts at

http://www.hindawi.com
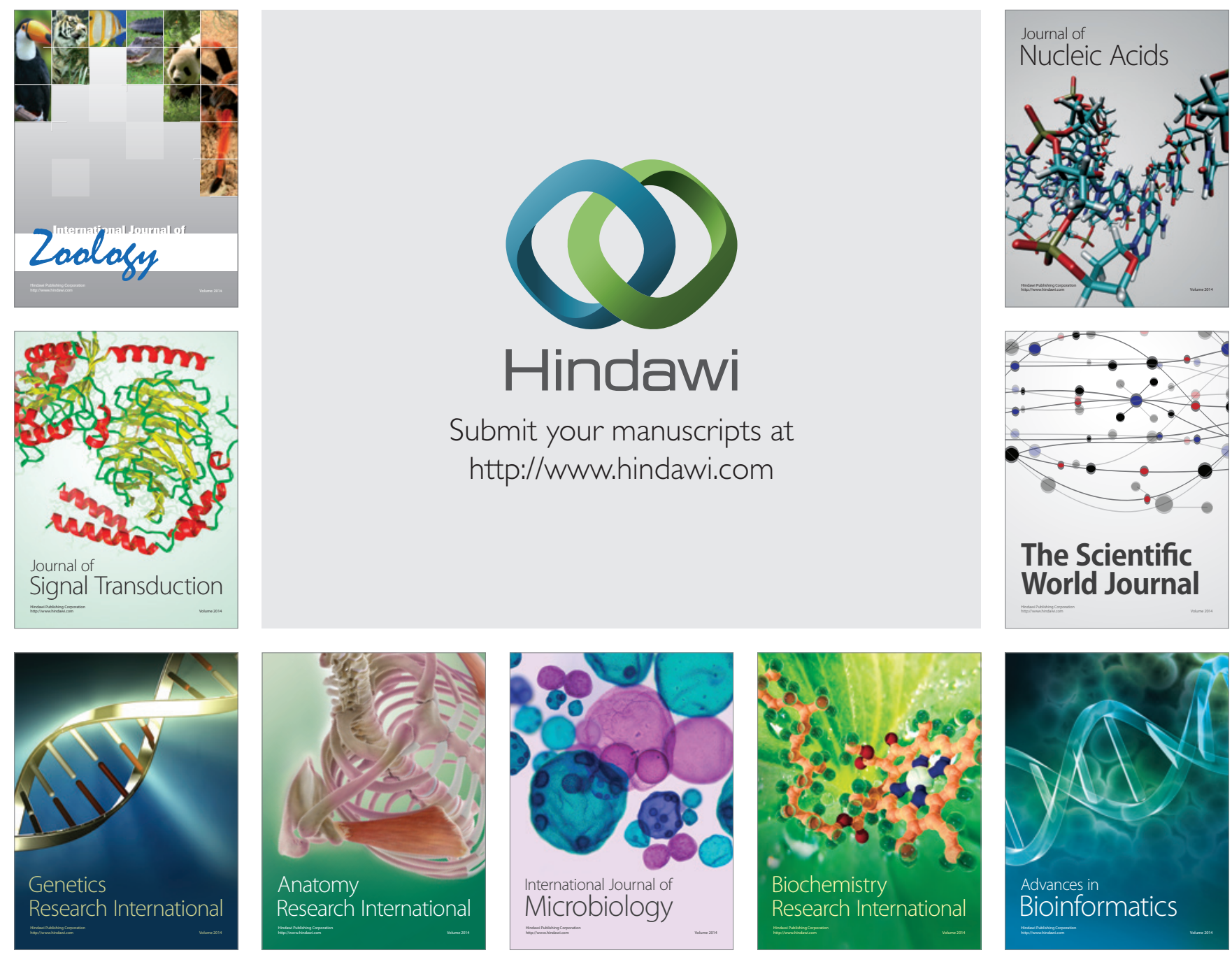

The Scientific World Journal
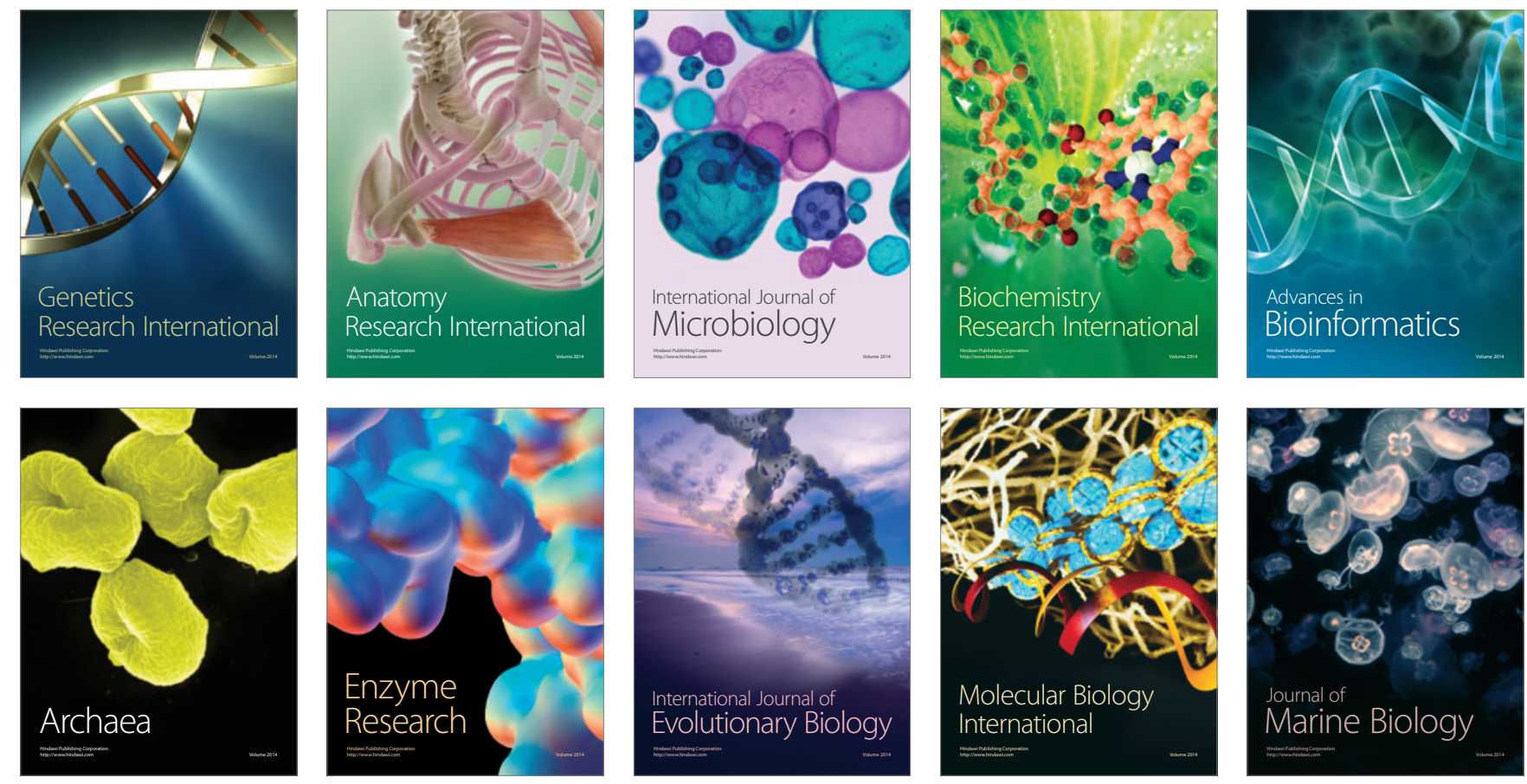